\title{
PH Adjusted for Body Temperature Measurement
}

National Cancer Institute

\section{Source}

National Cancer Institute. pH Adjusted for Body Temperature Measurement. NCI

Thesaurus. Code C161367.

The determination of the $\mathrm{pH}$, adjusted for body temperature, present in a sample. 